\title{
An investigation of dairy calf management practices, colostrum quality, failure of transfer of passive immunity, and occurrence of enteropathogens among Australian dairy farms
}

\author{
Angel Abuelo, ${ }^{1,2,3 *}$ Peter Havrlant, ${ }^{4}$ Natalie Wood, ${ }^{2} \dagger$ and Marta Hernandez-Jover ${ }^{2,3}$ \\ ${ }^{1}$ Department of Large Animal Clinical Sciences, College of Veterinary Medicine, Michigan State University, 736 Wilson Rd., East Lansing 48824 \\ ${ }^{2}$ School of Animal and Veterinary Sciences, Faculty of Science, Charles Sturt University, Locked Bag 588, Wagga Wagga NSW 2650, Australia \\ ${ }^{3}$ Graham Centre for Agricultural Innovation, Charles Sturt University and NSW Department of Primary Industries, Locked Bag 588, \\ Wagga Wagga NSW 2650, Australia \\ ${ }^{4}$ Wagga Wagga Agricultural Institute, NSW Department of Primary Industries, Private Mail Bag, Wagga Wagga NSW 2650, Australia
}

\section{ABSTRACT}

Calf preweaning morbidity and mortality risks have been reported as high in several countries, with average values approximating 35 and $7 \%$, respectively. However, limited data are available for calf morbidity and mortality risks on Australian dairy farms. The aims of this study were (1) to investigate current calf management practices on dairy farms in Australia and their association with herd-level morbidity and mortality using a questionnaire-based, cross-sectional study; and (2) to estimate the prevalence of common enteropathogens causing diarrhea, the failure of passive transfer of immunity, and poor colostrum quality in a sample of Australian dairy farms. We analyzed 106 completed questionnaires and samples from 23 farms (202 fecal, 253 calf serum, and 221 colostrum samples). Morbidity and mortality risks reported by farmers in preweaned heifers were 23.8 and $5.6 \%$, respectively. These risks were above the Australian dairy industry targets in 75.5 and $66.7 \%$ of respondents. The zoonotic pathogens Cryptosporidium spp. and Salmonella spp. were the most prevalent enteropathogens, with a true prevalence of 40.9 and $25.2 \%$, respectively. Salmonella O-group D was present in $67.9 \%$ of Salmonella-positive samples, followed by O-groups B (17.9\%) and C (10.7\%). Failure of transfer of passive immunity ( $\operatorname{IgG}<10 \mathrm{~g} / \mathrm{L})$ was observed in $41.9 \%$ of calves (mean herd-level prevalence of $36.2 \%$ ), and only $19.5 \%$ of colostrum samples met the standards for immunoglobulin content and microbiological quality. Collectively, these data indicate that there is still considerable room for improvement

Received March 6, 2019.

Accepted May 1, 2019.

*Corresponding author: abuelo@msu.edu

†Current address: Gunghalin Veterinary Hospital, 21 Crinigan Circle, Gungahlin ACT 2912, Australia. in calf-rearing practices on Australian dairy farms, particularly with regard to colostrum management and feeding hygiene.

Key words: calf health, diarrhea, heifer rearing, neonatal disease, replacement

\section{INTRODUCTION}

Calfhood diseases have a major effect on the economic viability of dairy operations, due to the costs associated with calf losses, treatments, and long-term effects on performance (Donovan et al., 1998). Replacement rearing represents 15 to $20 \%$ of total dairy production costs (Heinrichs, 1993). Therefore, health disorders among replacement stock significantly affect the sustainability of the dairy industry. Calf preweaning morbidity and mortality rates have been reported to be high (about $35 \%$ morbidity and 2.1 to $14 \%$ mortality) in several countries (Mee, 2013; NAHMS, 2014; Windeyer et al., 2014). However, to the best of our knowledge, no data have been reported on calf morbidity and mortality rates in Australian dairy farms.

Calf health and survival is affected by several farm management practices, such as calving intervention, colostrum administration, and feeding regimens (Murray et al., 2016). The majority of dairy farms in Australia are pasture-based (Dairy Australia, 2017b). Hence, several management practices differ significantly from the confined dairy systems common in North America or Europe. The Australian dairy industry has published best-practice guidelines on calf management from birth to weaning in the Australian dairy system (Dairy Australia, 2017a). Nevertheless, few data currently exist about on-farm management practices in dairy operations in Australia and their effects on calf health and survival.

Some studies have investigated colostrum quality parameters (Phipps et al., 2016; Chuck et al., 2017), 
the prevalence of failure of transfer of passive immunity (FTPI; Vogels et al., 2013), the prevalence of common enteropathogens causing neonatal calf diarrhea (NCD; Izzo et al., 2011b), and calf-rearing practices (Phipps et al., 2018) on Australian dairy farms. However, these studies were limited to a particular region and, to the authors' knowledge, no study has investigated these parameters together.

The current study had 2 aims: (1) to investigate current calf management practices on dairy farms in Australia and their association with herd-level morbidity and mortality; and (2) to estimate the prevalence of enteropathogens causing NCD, FTPI, and poor colostrum quality in a sample of Australian dairy farms using a pilot study.

\section{MATERIALS AND METHODS}

To achieve the aims of this study, the required information was gathered in 2 phases. Phase 1 involved a cross-sectional study using a questionnaire distributed among Australian dairy farms, and phase 2 involved a pilot study collecting and analyzing samples (fecal and serum samples from calves and colostrum) from a cohort of dairy farms.

\section{Ethical Considerations}

The procedures of this study were approved by the Animal Care and Ethics committee (protocol number A16062) and the Faculty of Science Human Research Ethics committee (protocol number 400/2016/14) of Charles Sturt University. Participation in the survey was voluntary. Animals were enrolled with the owner's written consent, and samples were collected by registered veterinarians.

\section{Cross-Sectional Study}

We distributed a 92-question survey about health management practices, morbidity, and mortality to dairy producers across Australia between December 2016 and December 2017. The survey was developed in consultation with specialist veterinarians and herd advisors.

Survey questions focused on topics relevant for morbidity and mortality because of their evidenced effect on calf health and survival according to the literature. The questionnaire was structured in 7 blocks: farm details, disease history, treatment protocol for diarrheic calves, calving management, feeding of calves (including colostrum management), housing and rearing, and other interventions (e.g., dehorning, castration). A copy of the survey is available from the corresponding author upon request. We piloted the questionnaire with 2 veterinarians external to the research team, 4 veterinary students at Charles Sturt University, and 3 local dairy producers to assess the respondents' answers and identify problematic questions. We then revised the survey before wider distribution. Because the revisions were minimal, we included the pilot surveys of local producers in the study as participants.

Distribution of the survey to all Australian dairy producers through a single organization (and as such, a sampling frame) was not possible, so we used a multi-pronged approach for distribution to maximize participation. We estimated the sample size required to obtain representation of dairy producers in Australia to be between 110 and 200, with the assumption that 20 to $25 \%$ of producers would conduct a specific practice (estimated prevalence), with $95 \%$ confidence level and 5 to $8 \%$ precision of the estimate. We distributed paper copies of the questionnaire to dairy producers attending various producers' meetings. A link to an online version of the survey (SurveyMonkey Inc., Palo Alto CA) was also circulated through producer-focused newsletters, magazines, and e-mail forums, as well as online via social media. As an incentive for participation, 4 gift cards worth $\mathrm{AU} \$ 50$ (1 AU $\$=\mathrm{US} \$ 0.78$ at the time of the study) from an Australian retailer were raffled among survey respondents.

\section{Pilot Study}

The collaboration of veterinary practices was sought for the collection of samples on farms. A brief description of the project was distributed to the members of the Australian Cattle Veterinarians (a special-interest group of the Australian Veterinary Association) in their electronic newsletter and through their e-mail distribution list. In brief, veterinarians were invited to collect serum, fecal, and colostrum samples from farms where they regularly worked. Sampling materials and freight costs were covered by project funding. The veterinarians received a copy of the laboratory results at no cost and were encouraged to share and discuss them with their clients. Veterinarians interested in participating were asked to contact the research team and were provided with sampling kits, consent forms, prepaid courier labels, and instructions related to sample collection, handling, and shipment.

Sample Collection, Shipment, and Processing. Veterinarians were asked to collect per farm (1) 7 to 12 blood samples from calves aged 1 to $7 \mathrm{~d}$ using vacuumed $10 \mathrm{~mL}$ serum tubes (BD Vacutainer; Becton Dickinson and Company, Plymouth, UK); (2) 7 to 12 
Table 1. Number (\%) of survey responses and fecal, serum, and colostrum samples analyzed by Australian state

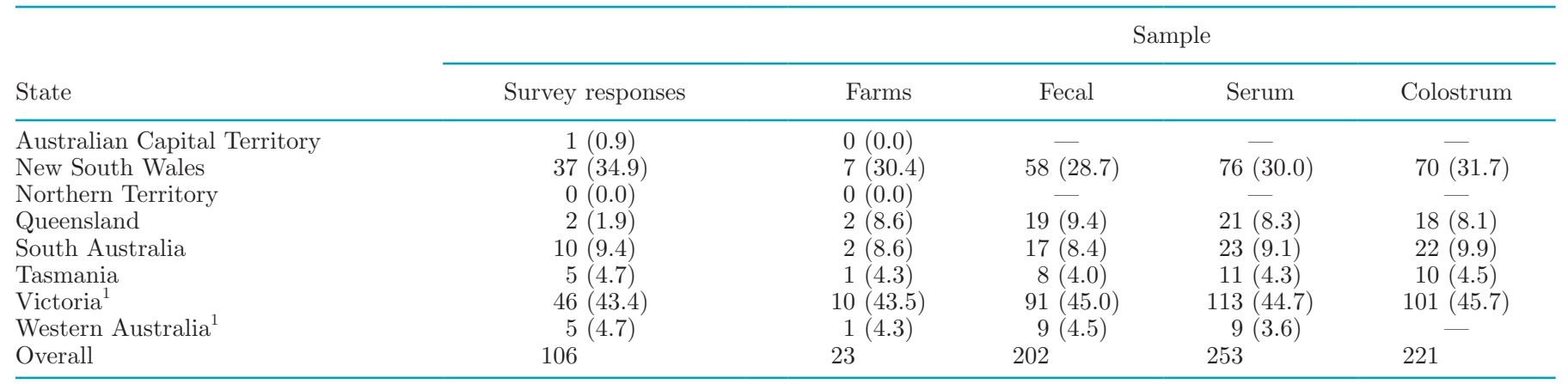

${ }^{1}$ Colostrum samples from 1 farm in Victoria and 1 in Western Australia were received thawed and excluded from analysis.

fecal samples from scouring calves younger than $21 \mathrm{~d}$ of age with a sterilized plastic container (Tube $70 \mathrm{~mL}$, $55 \times 44 \mathrm{~mm}$; Sarstedt AG \& Co., Adelaide, Australia); and (3) 7 to 12 colostrum samples using an identical sterile container directly from calf-feeding equipment. We requested that serum and fecal samples be maintained under refrigeration at $4^{\circ} \mathrm{C}$, and that colostrum be kept frozen at $-20^{\circ} \mathrm{C}$ to minimize the multiplication of bacteria. Samples were shipped under refrigeration by express courier to the Veterinary Diagnostic Laboratory at Charles Sturt University and processed upon receipt. Blood tubes were centrifuged at 2,000 $\times g$ for $10 \mathrm{~min}$ and the supernatant serum was harvested, aliquoted into $1.5-\mathrm{mL}$ microcentrifuge tubes, and immediately assayed for IgG quantification. Fecal samples were kept at $4^{\circ} \mathrm{C}$ until analysis within $12 \mathrm{~h}$. Colostrum samples were thawed at $4^{\circ} \mathrm{C}$ for $12 \mathrm{~h}$ before analysis. Colostrum samples from 2 farms $(n=19)$ were received defrosted and were excluded from the study. Overall, we analyzed a total of 202 fecal, 253 serum, and 221 colostrum samples from 23 different farms throughout Australia (Table 1).

Quantification of IgG. Serum and colostral IgG concentrations were determined using a commercial radial immunodiffusion assay (Bovine IgG test; Triple J Farms, Bellingham WA) following the manufacturer's instructions (http://69.195.120.15/jj.j/wp-content/ uploads/2017/04/Triple-J-Bovine-IgG-728411.pdf). In brief, serial dilutions of $1: 2$ and 1:4, and 1:2, 1:4, 1:8, and 1:16 were made with saline for each serum and colostrum sample, respectively. Bovine IgG standards were included in each determination for reference and ranged from 1.96 to $27.5 \mathrm{~g} / \mathrm{L}$. The diffusion ring through the agarose gel containing mono-specific antibody after $24 \mathrm{~h}$ of incubation at room temperature was measured using a caliper with precision of $0.1 \mathrm{~mm}$. The values of the sample's ring were read off the standard curve, giving a grams per liter value of IgG. Thresholds of $>10$ and $>50 \mathrm{~g} / \mathrm{L}$ for sera and colostrum, respectively, were used to classify satisfactory samples (Godden, 2008). Calves with serum IgG lower than $10 \mathrm{~g} / \mathrm{L}$ were classified as FTPI.

Identification of Enteropathogens. Fecal samples underwent rapid detection immunochromatography analysis using a commercially available assay (Rainbow Calf Scour 6; Bio-X Diagnostics, Jemelle, Belgium) to identify rotavirus, coronavirus, Cryptosporidium spp., and Escherichia coli following the manufacturer's instructions (Abuelo and Alves-Nores, 2016). Briefly, samples were diluted in a provided sample tube and homogenized by manually inverting before being placed into the strip tube. Following closure of the strip tube to allow the sample to diffuse along the strips, the devices were left vertical on a laboratory bench for $10 \mathrm{~min}$, and then read. Samples without a clear result for any of the pathogens (e.g., a weak positive reading or lack of negative control) were re-assayed, and if the same unclear result was obtained, were considered negative. A total of $7(3.5 \%)$ samples were re-assayed for one or more pathogens, and only one resulted in an unclear result for Cryptosporidium spp. after reanalysis.

We also tested fecal samples for Salmonella spp. using the PCR screening test described by Mainar-Jaime et al. (2013). Briefly, $10 \mathrm{~g}$ of feces were homogenized with $90 \mathrm{~mL}$ of sterile, buffered peptone water (Pail Buffered Peptone Water; Becton Dickinson and Company, Sparks, MD) and incubated for $18 \pm 2 \mathrm{~h}$ at $37 \pm 1^{\circ} \mathrm{C}$ for pre-enrichment. Then, DNA was extracted by the rapid boiling procedure from a $1 \mathrm{~mL}$ aliquot of diluted samples collected from the air-liquid interface (Oliveira et al., 2005). The primers $\mathrm{Fw}$ (5'-AGTGCTCGTTTACGACCTGAA-3') and Rv (5'-TGATCGATAATGCCAGACGA-3') were designed to amplify a 229-bp DNA fragment. The PCR mix was prepared with $5 \mu \mathrm{L}$ of extracted DNA, $18 \mu \mathrm{L}$ of $0.4 \mathrm{~m} M$ each primer, 0.2 $\mathrm{m} M$ each dNTP, $2.5 \mathrm{U}$ of REDTaq DNA Polymerase (Sigma Aldrich, Castle Hill, NSW, Australia), and 5 $\mu \mathrm{L}$ of $10 \times$ REDTaq PCR Reaction buffer (containing 
$11 \mathrm{mM} \mathrm{Mg}{ }^{2+}$; Sigma Aldrich) in a final total volume of $50 \mu \mathrm{L}$. After an initial denaturation step $\left(94^{\circ} \mathrm{C}, 5 \mathrm{~min}\right)$, PCR was performed by 40 cycles of denaturation at $94^{\circ} \mathrm{C}$ for $30 \mathrm{~s}$, annealing at $55^{\circ} \mathrm{C}$ for $30 \mathrm{~s}$, and extension at $72^{\circ} \mathrm{C}$ for $20 \mathrm{~s}$, with a final extension step at $72^{\circ} \mathrm{C}$ for 10 min. Double-distilled water and DNA extracted from a Salmonella Typhimurium strain (provided by the Veterinary Diagnostic Laboratory at Charles Sturt University), were used as negative and positive controls, respectively, in each PCR. The resulting PCR products were read through conventional electrophoresis in a 1.5\% (wt/vol) agarose gel and SYBR Green I nucleic acid gel staining (Sigma Aldrich). The PCR-positive samples were subsequently classified into O-antigen groups. Briefly, $50 \mu \mathrm{L}$ of the buffered peptone water pre-enriched fecal 1:10 dilution was plated in Salmonella-specific medium (CHROMagar Salmonella Plus; CHROMagar, Paris, France) and incubated for $24 \pm$ $2 \mathrm{~h}$ at $37 \pm 1^{\circ} \mathrm{C}$. Salmonella-typical colonies were subjected to serotypification using commercial monovalent anti-sera. A drop of antiserum was mixed with several colonies on a glass slide with an inoculating loop. After $10 \mathrm{~s}$, the agglutination reaction was assessed visually by holding the slide in front of a light source against a black background. Only sera against Salmonella Ogroups B (Salmonella O:6, 7, 8 Monovalent Antiserum; Bio-Rad Laboratories Pty Ltd., Gladesville, NSW, Australia), C (Salmonella O:4,5 Monovalent Antiserum; Bio-Rad), and D (Salmonella O:9 Monovalent Antiserum; Bio-Rad) were selected for analysis, because these represented the species of Salmonella most commonly isolated from calves in Australia (Izzo et al., 2011b).

Determination of Microbiological Contamination of Colostrum Samples. To evaluate the level of contamination in colostrum samples, we measured total aerobic bacterial count (TBC) and total coliform count (TCC). We prepared 10-fold serial dilutions of each sample in $9 \mathrm{~mL}$ of sterilized PBS (Sigma Aldrich). For TBC, plates were prepared by placing $100 \mu \mathrm{L}$ of each relevant dilution in sterile Petri dishes and adding sterilized plate count agar (Becton Dickinson), previously cooled to $50^{\circ} \mathrm{C}$, into each plate before mixing and allowing to solidify. The TCC was prepared as described above, apart from the use of violet red bile agar (Becton Dickinson) instead of plate count agar. Plating was carried out in duplicate for each sample. The TCC and $\mathrm{TBC}$ plates were incubated at $30^{\circ} \mathrm{C}$ and $37^{\circ} \mathrm{C}$ for $72 \mathrm{~h}$ and $24 \mathrm{~h}$, respectively. Duplicate plates containing colonies within the range of 30 to 300 were used to calculate mean colony forming units per milliliter in the original samples. Cut-off points of 100,000 and 10,000 $\mathrm{cfu} / \mathrm{mL}$ for TBC and TCC, respectively, were used to classify samples as satisfactory or unsatisfactory (Godden, 2008).

\section{Data Analyses}

Paper-based questionnaires were added into the online system, and answers were downloaded in spreadsheet format (Excel, Microsoft Corp., Redmond, WA) and exported into JMP Pro v.14 (SAS Institute Inc., Cary, NC) for statistical analysis. All responses were evaluated and screened for completeness independently by 2 of the authors. From the 121 responses received, 15 were incomplete and removed from the final pool of answers. A final number of 106 completed surveys were therefore analyzed.

Data from the questionnaire were initially examined using descriptive statistics, for data cleaning and to determine distributions. Categorical data are reported as the number of responses and percentages, whereas continuous data are reported as mean $[ \pm$ standard deviation (SD)] and quartiles. To investigate associations between on-farm calf health management practices and herd-level morbidity and mortality, we conducted univariable linear regression analyses. The outcome variables considered were mortality risk, overall morbidity risk, and scour and pneumonia morbidity risks. Associations between explanatory variables and the outcome of the model with a $P$-value $<0.05$ were considered significant. We considered multivariate analysis, but did not use it because of the limited associations found at a univariate level.

We estimated the apparent prevalence (AP) of each studied enteropathogen as the proportion of positive fecal samples from the total fecal samples collected at farm and study levels. The methods employed for enteropathogen identification are not the considered the gold standard, so we also estimated the true prevalence (TP) of each pathogen based on reported test sensitivity and specificity values (Table 2 ) following the formula described by Rogan and Gladen (1978):

$$
\mathrm{TP}=\frac{\mathrm{AP}+\text { Specificity }-1}{\text { Sensitivity }+ \text { Specificity }-1} .
$$

The radial immunodiffusion test used is considered the gold standard for quantification of IgG in bovine colostrum and serum samples. Therefore, we assumed that the estimated prevalence of FTPI was the TP.

\section{RESULTS AND DISCUSSION}

All the descriptive results from the questionnaire are available in Supplemental Table S1 (https://doi.org/ 10.3168/jds.2019-16578). We identified limited significant associations between the studied calf management practices and the outcome variables in the univariate linear regression, and these failed to achieve significance 
Table 2. Reported sensitivity and specificity of the tests used to identify pathogens in fecal samples

\begin{tabular}{lccl}
\hline Pathogen & Sensitivity, $\%$ & Specificity, $\%$ & Reference \\
\hline Escherichia coli F5 & 100 & 100 & Dieguez et al. (2012) \\
Rotavirus & 95.0 & 93.7 & Dieguez et al. (2012) \\
Coronavirus & 84.6 & 79.5 & Dieguez et al. (2012) \\
Cryptosporidium spp. & 94.2 & 88.2 & Dieguez et al. (2012) \\
Salmonella enterica & 98.0 & 96.0 & Malorny et al. (2003) \\
\hline
\end{tabular}

at the multivariate level. Therefore, only the descriptive questionnaire results and the pilot study data are presented and discussed.

\section{Characteristics of Survey Respondents}

Holstein-Friesian was the main breed for $64.2 \%$ of respondents, followed by Jersey (14.2\%) and Holstein/ Jersey cross (12.3\%). Other breeds, such as Brown Swiss, Ayrshire, Australian Red, or Illawarra represented less than $10 \%$ of the responses. The majority of responses originated from farms in the state of Victoria, followed by New South Wales (Table 1). Among respondents, the mean $(\mathrm{SD})$ and median (interquartile range) size of the milking herd were 440 (326.1) and 330 (345) animals, respectively. Farm operations with 251 to 500 milking cows were most common among respondents $(36.8 \%)$, followed by farm sizes of 101-250 cows (30.2\%), 501-1,000 cows (24.5\%), >1,000 cows (4.7\%), and $<100$ cows $(3.8 \%)$. Overall, the distributions of breed, location, and herd size among respondents were similar to the values reported for the overall Australian dairy industry (Dairy Australia, 2017b).

\section{Morbidity and Mortality}

Survey questions pertained to heifer calves only, because male calves are often removed from farms shortly after birth on many Australian dairies. The mean (SD) mortality risk in preweaned heifer calves reported by farmers was $5.6 \%$ (3.75). Of this, $66.7 \%$ of respondents reported mortality risks higher than the $3 \%$ industry target (Dairy Australia, 2017a), and 9.8\% of respondents documented mortality risks higher than $10 \%$. In addition, reported mean (SD) morbidity due to diarrhea and respiratory disease in preweaned heifers were $17.9 \%$ (15.44) and $6.0 \%$ (8.34), respectively. The Australian dairy industry does not have published independent benchmarks for these diseases. Instead, they recommend a preweaning illness risk of lower than $10 \%$ (Dairy Australia, 2017a). When the number of reported cases of diarrhea and pneumonia were combined, the mean (SD) illness risk was $23.8 \%$ (19.90); only $24.5 \%$ of respondents met the preweaning illness rate target.
Morbidity and mortality risk were not affected by herd size or geographic location $(P>0.05)$.

Collectively, these data suggest that the calf morbidity and mortality risks reported by farmers are higher than industry-recommended targets in a great proportion of Australian dairy farms. However, we noted a great variation among survey respondents, with illness and mortality risks ranging from 0.0 to $87.5 \%$ and 1.0 to $26.7 \%$, respectively. Our statistical analysis of the data did not identify a significant association between farm calf management practices and reported mortality, diarrhea/pneumonia morbidity, or overall illness risks. This could be attributed to the high variation in different calf management practices among the farms in our data set. Nevertheless, the fact that preweaning mortality and morbidity rates were met by a third and a quarter of respondents, respectively, indicates that industry targets are achievable, and this information can be used to motivate farmers with risks above the recommended levels.

\section{Colostrum Quality}

A total of 221 colostrum samples from 21 different farms were analyzed for IgG content, TBC, and TCC (Table 3). Satisfactory IgG concentrations (>50 g/L) were obtained in $105(47.5 \%)$ samples, and $129(58.4 \%)$ and $160(72.4 \%)$ of the samples met the recommended industry standards for TBC and TCC, respectively. However, when all the current recommendations were considered, only 43 samples $(19.5 \%)$ met all criteria. These findings were consistent with a previous study conducted in 24 farms in northern Victoria (Australia), where only $23 \%$ of colostrum samples met the 3 standards (Phipps et al., 2016). Similar to our results, this study also reported that more than $50 \%$ of studied samples contained a concentration of IgG lower than recommended and a high bacterial contamination in approximately $40 \%$ of samples. Nevertheless, the proportion of satisfactory samples was lower than in a study in the United States, in which $39.4 \%$ of samples met all the standards (Morrill et al., 2012). A high proportion of colostrum samples above TBC and TCC thresholds has also been reported in Ireland (McAloon et al., 2016). 
CALF MANAGEMENT IN AUSTRALIAN DAIRY FARMS

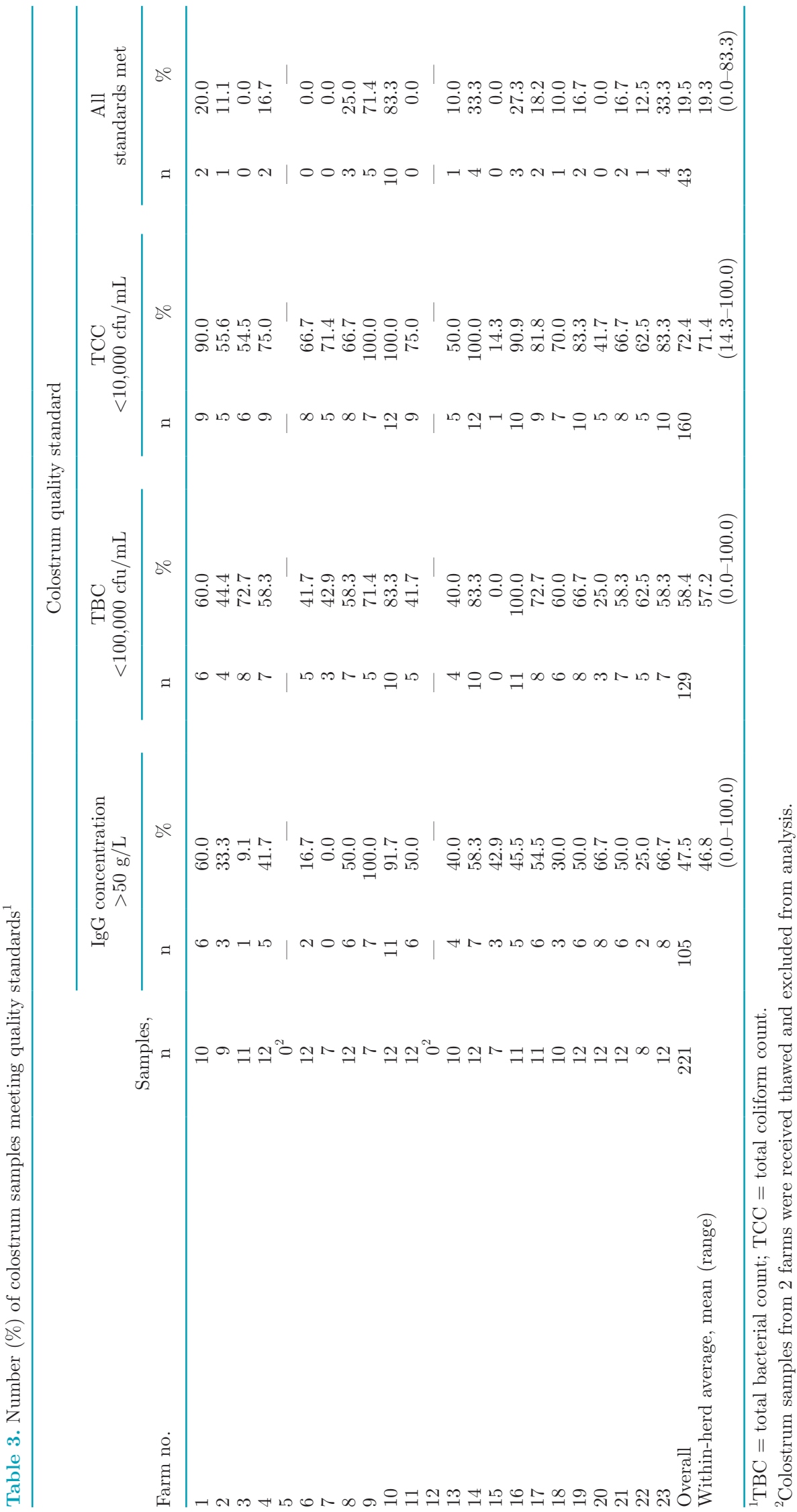


The present study demonstrates that a significant proportion of colostrum on Australian dairy farms may contain bacterial counts above industry recommendations. Elevated colostral TBC and TCC not only act as a vehicle for the transmission of organisms but also represent a significant risk for FTPI by decreasing the efficiency of absorption of immunoglobulins (Johnson et al., 2007; Gelsinger et al., 2015). The harvesting stage has been suggested as the point at which the majority of contamination is most likely to occur (Stewart et al., 2005). However, we observed a great variation among farms in the proportion of colostrum samples meeting all quality standards, with an average of $19.3 \%$ and a range of 0.0 to $83.3 \%$, suggesting farm-specific factors influence the degree of colostrum contamination. Hence, veterinarians are required to conduct further investigations on each farm to identify where contamination is likely to occur. The prompt refrigeration of colostrum (within $1 \mathrm{~h}$ of collection) and thorough disinfection of the calf-feeding apparatus before use have been recommended to reduce bacterial contamination (Phipps et al., 2016).

In addition to bacterial contamination, more than $50 \%$ of the studied colostrum samples had suboptimal IgG concentrations. This highlights the need to estimate colostrum IgG content before administering it to calves. This can be accurately done on farms using a colostrometer or a Brix refractometer (Bartier et al., 2015). Indeed, the Australian dairy industry recommends the routine use of Brix refractometry because of its reliability for on-farm use (Dairy Australia, 2017a). However, only $51 \%$ of survey respondents routinely estimate colostrum IgG content with validated methods [i.e., a colostrometer $(3.8 \%)$ or a Brix refractometer $(47.2 \%)]$. The remainder of the respondents reported either not routinely checking colostrum quality (21.7\%) or performing only a visual assessment (24.5\%), a very inaccurate method (Abuelo and Alves-Nores, 2016).

Taken together, the colostrum quality results suggest that a large number of calves are at risk of receiving colostrum with elevated bacterial counts and low immunoglobulin content, making them more susceptible to FTPI and negatively affecting calf health and the economy of the dairy enterprise. Additionally, the degree of colostrum contamination should be taken into consideration when assessing colostrum management on farms.

\section{FTPI Prevalence}

We also estimated the prevalence of FTPI in 23 farms. The concentration of serum IgG was measured in a total of 253 calves within their first week of age.
The overall and mean (range) within-herd prevalences of FTPI were 41.9 and $36.2 \%$ (0.0-83.3\%), respectively. Vogels et al. (2013) estimated FTPI among 100 herds in southwest Victoria measuring serum total protein, also finding a high prevalence: $38 \%$ of calves experienced FTPI and more than two-thirds of the herds had more than $25 \%$ of calves with FTPI. Our survey found that $23.6 \%$ of respondents let calves suck colostrum from their dams and $71.6 \%$ separated calves from their dams $>6 \mathrm{~h}$ after calving. In fact, $41.8 \%$ of respondents separate calves $>12 \mathrm{~h}$ after birth. Relying on the calf sucking colostrum from their dam and late separation are known to increase the prevalence of FTPI (Besser et al., 1991; Vogels et al., 2013). Therefore, collecting calves from the calving area more frequently and feeding them quality-tested colostrum immediately after removal will likely reduce the high prevalence of FTPI.

Calves with FTPI have higher risks of mortality, respiratory disease, diarrhea, and overall morbidity, as well as an estimated decrease in ADG of $81 \mathrm{~g} / \mathrm{d}$ (Raboisson et al., 2016). Estimates of the cost of a case of FTPI under the Australian dairy systems are, to our knowledge, not available. However, the total cost per dairy calf with FTPI was estimated to be $€ 60$ (95\% CI: $€ 10$ to $€ 109$ ) in European cattle systems (Raboisson et al., 2016). The high prevalence of FTPI we observed not only affects calf health but is also likely to have a significant economic impact on the farm. However, only $13.2 \%$ of survey respondents reported undertaking some assessment of FTPI on their farms. This practice allows for monitoring of adequate immune transfer and can be easily performed at the farm using various methods (Abuelo and Alves-Nores, 2016). Routine monitoring of FTPI should be incorporated into the herd health protocols of Australian dairy farms to improve colostrum management and reduce FTPI prevalence.

\section{Diagnosis and Treatment of Diarrheic Calves}

Farmers were asked about how they diagnose and treat calves with NCD. All but 3 of the 106 survey respondents reported having at least 1 case of NCD in the previous year. In $83 \%$ of farms, calves are usually still housed when they start scouring. The onset of diarrhea is more common in calves aged 6 to $21 \mathrm{~d}(64.1 \%$ of respondents), followed by calves aged 0 to $5 \mathrm{~d}(32.1 \%)$. The majority of respondents $(71.7 \%)$ diagnosed diarrhea themselves; only 17.9 and $7.6 \%$ of the farmers reported that the diagnosis was made by a veterinarian through either a visit or a conversation, respectively. Furthermore, $55.8 \%$ of farmers did not regularly require veterinary consultation for the treatment of NCD, and $33.0 \%$ of respondents always administered antimicro- 
bials for cases of NCD. Although a larger proportion of farmers $(49.1 \%)$ reported using antimicrobials only when the calves were systemically ill, following the current recommendation (Constable, 2004), an important proportion of farmers still administered antimicrobials as a blank treatment for NCD. This results in the use of antimicrobials when they are not needed and generates reservoirs of resistance among both commensal and pathogenic bacteria (Catry et al., 2016). Increasing awareness among farmers about the judicious use of antimicrobials for treating NCD is required.

In addition, $63.2 \%$ of respondents systematically withheld milk from calves with NCD: $29.7 \%$ did it for at least $24 \mathrm{~h}$ and $7.6 \%$ until the calves recovered from NCD. This was consistent with the finding that $55.7 \%$ of respondents fed oral rehydration solutions instead of milk or milk replacer to calves with NCD. Previous studies demonstrated weight loss in calves fed only oral rehydration solutions, compared to weight gain in those that received milk in addition to oral rehydration (Fettman et al., 1986; Garthwaite et al., 1994). Indeed, even hypertonic oral solutions (with a high concentration of glucose) cannot provide sufficient energy for maintenance and growth (Constable et al., 2001). However, the severity or duration of diarrhea is not different between calves that receive milk in addition to oral rehydration compared with oral rehydration alone (Garthwaite et al., 1994). Thus, it is currently recommended to continue feeding milk to calves with NCD and only to withhold it for periods up to $12 \mathrm{~h}$ in severe cases (Smith, 2009; Lorenz et al., 2011; Smith and Berchtold, 2014). The labels of most commercially available rehydration products in Australia were updated in 2014 to instruct farmers to continue the administration of milk-based products when using oral rehydration electrolytes (APVMA, 2018). Based on the results of this survey, however, many farmers still need this information. In Europe, legislation details the minimum requirements for commercial oral rehydration products for calves (European Commission, 2014), but this is not the case in other countries, including Australia and the United States. Significant variability in the quality of commercial oral electrolyte solutions available in the United States and Australia has been noted (Smith, 2009; Vogels, 2010). Veterinarians need to be proactively involved in establishing guidelines for the use of specific oral rehydration products.

Overall, these results might suggest that there is still significant room for veterinarians to become more involved in calf health programs in Australian dairy farms. However, previous research has highlighted the differences in perceptions of topics of discussion during farm visits between veterinarians and farmers (Hall and
Wapenaar, 2012). Therefore, improving effective communication between farmers and veterinarians should not be overlooked when transmitting and explaining evidence-based recommended practices.

\section{Pathogens Causing Diarrhea}

Samples for the laboratory diagnosis of diarrhea were reported to have been collected by $55.7 \%$ of the farmers completing the survey. Of these, Cryptosporidium parvum was isolated in $64.4 \%$ of farms, followed by Salmonella enterica (52.5\%), rotavirus (49.1\%), coronavirus (40.7\%), and E. coli (35.6\%).

We analyzed 202 fecal samples from diarrheic calves aged $11.3 \pm 5.29 \mathrm{~d}$ (mean $\pm \mathrm{SD}$ ) from 23 farms for the presence of common NCD enteropathogens. Overall, 70 samples $(34.7 \%)$ were positive for a single pathogen, $76(37.6 \%)$ for 2 pathogens, $33(16.3 \%)$ for more than 2 pathogens, and $23(11.4 \%)$ were negative for all pathogens investigated. Coinfection is frequent in NCD, with 5 to $71 \%$ of mixed infections being reported in the literature worldwide (de la Fuente et al., 1998; Uhde et al., 2008; Izzo et al., 2011b). The proportion of mixed infections detected in our study $(53.9 \%)$ was lower than the $71 \%$ reported by the only previous Australian study (Izzo et al., 2011b). However, the previous study focused only on samples collected from outbreaks of diarrhea, which might have increased the proportion of mixed infections, because these usually result in a more severe clinical presentation (Reynolds et al., 1986; Gulliksen et al., 2009).

Overall, the most prevalent enteropathogen identified in the diarrheic fecal samples was Cryptosporidium spp. ( $\mathrm{TP}=40.9 \%$ ), followed by Salmonella spp. (TP $=25.2 \%)$, rotavirus $(\mathrm{TP}=19.1 \%)$, E. coli $\mathrm{F} 5(\mathrm{TP}=$ $13.9 \%$ ), and coronavirus ( $\mathrm{TP}=7.4 \%$ ). These results from on-farm collection were consistent with the results of the survey, which also found Cryptosporidium spp. and Salmonella spp. to be the most common enteropathogens. The within-herd prevalence of each pathogen varied considerably among farms in the pilot study (Table 4). For example, the TP of Cryptosporidium spp. and Salmonella spp. varied between 0.0 and $100.0 \%$ (mean: $44.1 \%$ and $27.5 \%$, respectively) and the $\mathrm{TP}$ of coronavirus ranged from 0.0 to $57.2 \%$ (mean: 13.3\%). The ELISA pathogen identification assay we used detects Cryptosporidium spp., but data worldwide show that Cryptosporidium parvum is the most common species found in calves of this age (Geurden et al., 2007; Langkjaer et al., 2007; Xiao et al., 2007). Reports from Europe, the United States, and Australia indicate that Cryptosporidium spp. are among the most common enteropathogens isolated in cases of NCD, 
with a prevalence ranging from 15 to $59 \%$ (de la Fuente et al., 1999; Björkman et al., 2003; Uhde et al., 2008; Gulliksen et al., 2009; Izzo et al., 2011b). Furthermore, several studies indicate that infection rates in young dairy calves with Cryptosporidium parvum are as high as 100\% in some herds (de Graaf et al., 1999; O'Handley et al., 1999, Olson et al., 2004; Abuelo, 2016), which we also observed in the present study. Only one drug, halofuginone lactate, is currently licensed for the prevention and treatment of cryptosporidiosis in calves in Australia. However, some controversy exists regarding the effectiveness of this drug to treat established Cryptosporidium infections (Silverlås et al., 2009; Trotz-Williams et al., 2011). Therefore, enhancing calf immunity and reducing the exposure of the calves to the pathogen through appropriate management and hygiene practices are key to reducing the incidence of cryptosporidiosis in calves.

Salmonella O-group D was isolated in 38 of the 56 samples $(67.9 \%)$ positive on initial PCR screening in this study. This O-group includes Salmonella Dublin, which is the most common serovar identified in calves from this antigenic group, and an important serotype due to its ability to create a long-term carrier status with intermittent shedding (Nielsen et al., 2004). Salmonella O-groups B and C were identified in 10 $(17.9 \%)$ and $6(10.7 \%)$ PCR-positive samples, respectively. These serogroups include the serovars Salmonella Typhimurium and Salmonella Bovismorbificans as the more common serovars identified in calves (Grimont and Weill, 2007). Two PCR-positive samples from the same farm were negative to all the O-groups tested and subsequent serotypification was not undertaken. Similar data were presented in an earlier Australian report, which identified Salmonella Dublin as the most common serovar, followed by Salmonella Typhimurium and Salmonella Bovismorbificans (Izzo et al., 2011a). Cryptosporidium parvum and Salmonella Typhimurium are known to cause disease in humans and they were identified in $40.9 \%$ and $5.4 \%$ of samples from diarrheic calves, respectively. These findings highlight the zoonotic potential of NCD with approximately half of the cases being caused by zoonotic agents. Therefore, the need for personal protection must be reinforced to people in contact with calves to prevent infections. Indeed, outbreaks of human cryptosporidiosis associated with an epizootic in calves have been reported (Reif et al., 1989), and it is estimated that about 1 in every 6 human cryptosporidiosis cases comes from animals, calves (both beef and dairy) being the most common animal sources (Cacciò and Putignani, 2014).

Rotavirus has usually been identified in combination with another pathogen(s) as the most or second most prevalent (de la Fuente et al., 1999; Björkman et al., 2003; Uhde et al., 2008; Izzo et al., 2011b). In our study, rotavirus was the third most commonly isolated pathogen, with a TP of $19.1 \%$, lower than the $79.9 \%$ reported by Izzo et al. (2011b). However, this difference might be explained by the source of the samples; compared with the previous study, our samples did not originate from outbreaks of NCD, in which mixed infections are common (de la Fuente et al., 1998; Uhde et al., 2008; Smith, 2012). Similarly, the TP of E. coli F5 (13.9\%) was lower than in other studies, some of which reported prevalences up to $75.6 \%$ (El-Seedy et al., 2016). However, NCD caused by $E$. coli is most prevalent within the first 4 to $7 \mathrm{~d}$ of life (Foster and Smith, 2009), so age differences among studies might explain the variation observed in the prevalence of E. coli NCD. Indeed, only 42 of the 202 fecal samples $(20.8 \%)$ came from calves younger than 1 wk of age, and the TP of E. coli in this subgroup reached $69.0 \%$ (data not shown). Coronavirus was the least prevalent pathogen in the present study $(\mathrm{TP}=7.4 \%)$. Several studies have also reported low prevalence of coronavirus in NCD, with documented prevalence ranging between 7.8 and $14 \%$ overseas and $21.6 \%$ in Australia (Reynolds et al., 1986, de la Fuente et al., 1999; Uhde et al., 2008; Gulliksen et al., 2009; Izzo et al., 2011b). Neonatal calf diarrhea caused by rotavirus, coronavirus, and $E$. coli can be effectively prevented by vaccinating dams before calving to increase specific immunoglobulins in colostrum (Kohara et al., 1997). Nevertheless, only $22.6 \%$ of survey respondents reported vaccinating dams for this purpose. Therefore, calf health could be further improved by vaccinating dams during the dry period and ensuring that calves receive adequate amounts of good-quality colostrum in a timely manner.

A total of 23 samples (11.4\%) were negative for all pathogens tested, including all 8 samples submitted from 1 farm. These negative results could be from cases of NCD caused by malnutrition or rapid change in diet, pathogens not included in this investigation, or by false negatives, especially for pathogens with low or intermittent shedding. Repeated sampling of negative animals was not attempted.

\section{Feeding and Housing}

The majority of respondents $(89.6 \%)$ fed fresh whole milk to their calves; a small proportion fed milk replacer alone $(7.5 \%)$ or whole milk supplemented with milk replacer $(2.8 \%)$. The supplementation of whole milk with milk replacer aims to provide high-energy, high-protein feed in a smaller volume than would otherwise be required to achieve a similar nutritional 
CALF MANAGEMENT IN AUSTRALIAN DAIRY FARMS

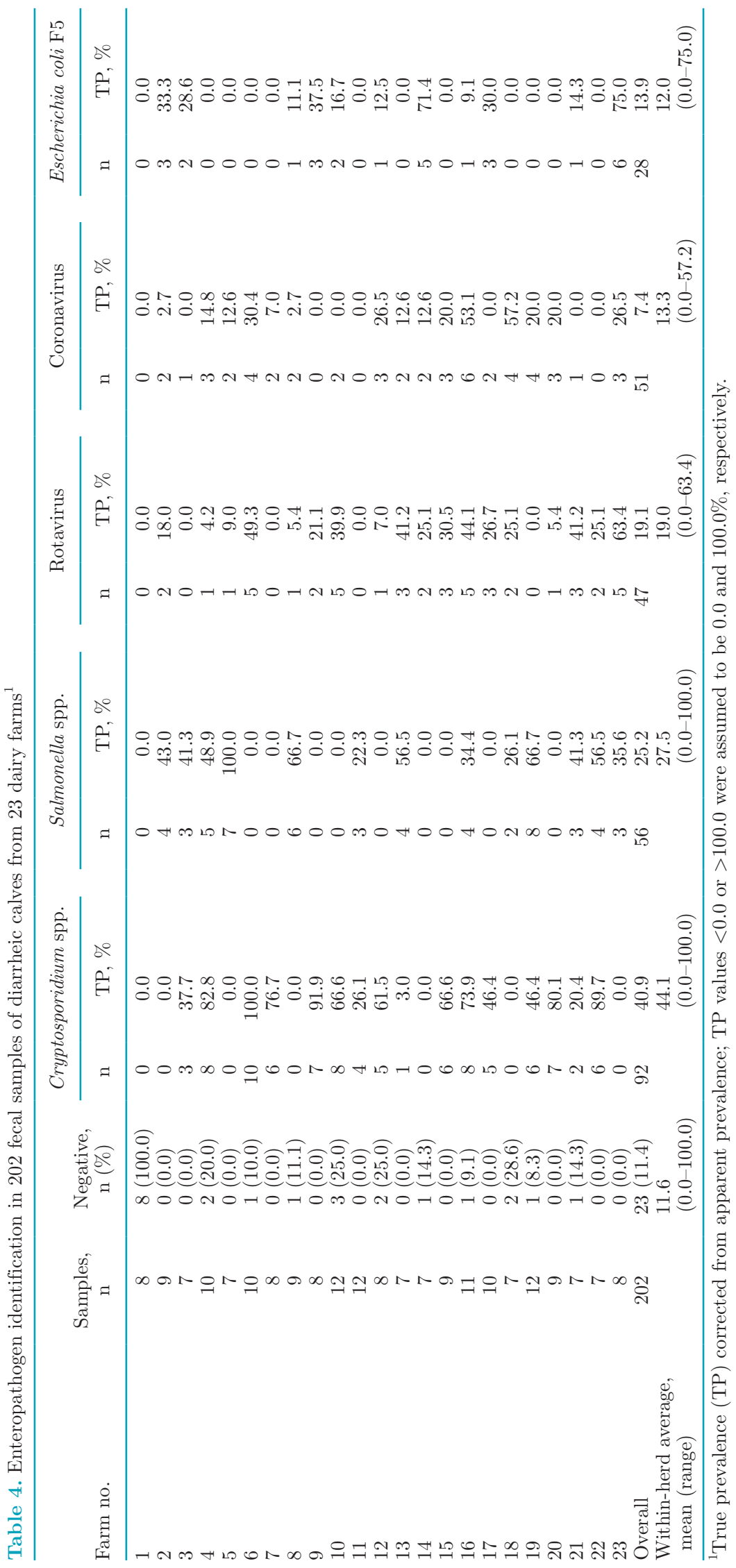

Journal of Dairy Science Vol. 102 No. 9, 2019 
content if using whole milk or milk replacer alone, thus allowing optimal growth rates to be achieved without the need to feed high volumes of milk (Dairy Australia, 2017a). Nevertheless, the mean (SD) volume of milk/ milk replacer fed to dairy calves up to 2 wk of age and from 3 wk onwards was 4.4 (1.47) L and 6.1 (2.11) L, respectively. The Australian recommendations for milk volume to be fed to calves is 10\% BW (Dairy Australia, 2017a). Preweaning nutrition and thus preweaning ADG has lasting effects on subsequent lactation and reproductive performance (Kertz et al., 2017). The volumes of milk fed by the majority of respondents were representative of conventional restricted milk feeding programs (Drackley, 2008). Calves under these programs show lower ADG, greater risk of disease, and achieve first service later than calves fed under an intensive feeding program (Curtis et al., 2018). On the other hand, restrictive milk feeding programs allow for weaning at an earlier age than intensive feeding programs (Drackley, 2008). However, the mean (SD) age at weaning in our survey was 79.1 (28.45) d, similar to the mean (SD) weaning age of $10.2(2.53)$ wk reported by Phipps et al. (2018), but higher than the 8 wk recommended for intensive feeding (Eckert et al., 2015). Nevertheless, several other factors, such as concentrate intake and weight, need to be considered when deciding when to wean calves, and this might explain the differences in weaning age compared with North American dairy systems. Indeed, it is important to consider that most of the previous studies of calf-feeding programs were performed in different dairy production systems; further research is needed to determine the benefits and cost-effectiveness of calf intensive feeding programs in the Australian pasture-based system.

Routine feeding of waste milk to calves was performed by $71.7 \%$ of the respondents. Of these, $81.6 \%$ reported routinely feeding milk from cows with mastitis and $71.7 \%$ used milk from cows that had been treated with antimicrobials. These practices have also been reported to be common in other countries (Brunton et al., 2012; Duse et al., 2013), in an attempt to reduce calf-rearing costs by using milk that would otherwise be discarded. Early evidence reported that these practices resulted in no differences in growth or morbidity compared with control milk (Kesler, 1981). However, they have been associated with higher levels of antimicrobial-resistant bacteria in the gastrointestinal tracts of calves (Aust et al., 2013; Duse et al., 2015). Also, feeding mastitis milk to calves is a risk factor for heifer mastitis (Parker et al., 2007; Ivemeyer et al., 2009). These practices should be avoided not only to improve animal health but to prevent potential downstream implications for human health.
Milk-based feedings were administered predominantly using plastic calf feeders (67.0\%); bucket and automatic feeding was used by $12.3 \%$ and $6.6 \%$ of respondents, respectively. Feeding devices can serve as fomites for pathogen transmission. Indeed, $73.8 \%$ of the farms using calf feeders used the same feeder in multiple pens, without cleaning feeders $(40.6 \%)$ or using only water $(13.2 \%)$ between pens. Calves that share feeding devices have a higher odds of respiratory disease (Svensson et al., 2003; Lundborg et al., 2005), which can be due to the transmission of pathogens via the use of the same nipple. The median (SD) number of teats per feeder was 6 (5.72) and 14 (17.29) up to 2 wk of age, and from $3 \mathrm{wk}$ of age until weaning, respectively. Thus, the opportunities for disease transmission between animals via feeders are considerable if appropriate sanitation and disinfection practices are not in place.

Calves were housed for an average (SD) of 36.8 (28.53) d after birth. We observed considerable variation in housing type for preweaned heifers. A closed barn (calves totally inside) with calves kept in groups was the most common housing method (51.9\%), followed by an open barn (calves have free access to outside; $19.8 \%$ ), a patio barn (calves kept inside with a restricted area open to outside; $17.9 \%$ ), and individual hutches (11.3\%). Calves being kept totally outside $(4.7 \%)$ or kept individually inside a closed barn $(2.8 \%)$ were the least common housing methods. For animals kept in groups, the size of the groups varied considerably. The median (SD) maximum number of calves per pen was 10 (10.71), with a range of 4 to 80 calves per pen. However, $86.4 \%$ of respondents did not keep calves of different ages together in the same pen, and although male calves were housed in the same shed as female calves by $54.7 \%$ of respondents, $44.8 \%$ kept them in separate pens in the same sheds. Also, $54.7 \%$ of respondents reported having at least 1 pen designated for sick animals on their farm, and $17.0 \%$ had a sick pen in each calf facility. Nevertheless, $76.4 \%$ of the farms did not have solid partitions between pens, which facilitates nose-to-nose contact and disease transmission among animals in the same shed (Lago et al., 2006). Individual housing was used by only $14.1 \%$ of respondents, in contrast to with data from the United States, where approximately $70 \%$ of farms house preweaned heifer calves individually (NAHMS, 2014). However, group housing improves solid feed intake and calf weight gain, as well as calf behavioral aspects, without adversely affecting calf health in well-managed herds (Costa et al., 2016). Thus, although group-housed calves might be at a higher risk of disease transmission, the benefits associated with socialization likely outweigh this risk, provided calves are managed appropriately. 
Woodchips were the most common bedding material used $(39.6 \%)$, followed by straw (31.1\%), rice hulls $(16.0 \%)$, and sawdust (14.1\%). Straw is commonly recommended in areas of cold climate to allow nesting to counteract temperature loss (McGuirk, 2011). However, this might be less relevant in Australia's more moderate climate. The hygiene of the environment and frequency of cleaning are likely of greater relevance for disease transmission. Pens were cleaned only before the calving season by $36.2 \%$ of respondents, but cleaned weekly, fortnightly, and monthly in $17.5 \%$, $28.8 \%$, and $17.5 \%$ of farms, respectively. A substantial proportion of respondents $(24.5 \%)$ selected a cleaning frequency that was not one of the main options given on the survey: $16.0 \%$ cleaned pens as needed through visual assessment, and 8.5\% cleaned after each group or calf (individual housing). Complete replacement of litter was the most common cleaning method (57.5\%), followed by adding more litter to the pen (30.0\%) and spraying disinfectant onto the litter $(5.0 \%)$.

\section{Study Limitations}

We were unable to calculate a survey response rate because we could not track the number of farmers who received the study information. Considering that Australia had 5,789 registered dairy farms in 2016 (Dairy Australia, 2017b), only 1.77\% of Australian dairy farmers responded to the survey. However, the distribution of responses per Australian state in our survey was similar to the distribution of registered dairy farms (Dairy Australia, 2017b), so our results include the different dairy production systems present in the country. Nonetheless, self-selection bias is also inherent in these types of studies, so the results of the current study cannot be generalized to the entire target population. However, given the current lack of studies investigating dairy calf management practices at the Australian national level, this study provides useful information on what areas appear to need more attention by farmers, veterinarians, and extension agents.

Similarly, the collection of farm samples depended on the willingness of veterinarians and farmers to collaborate with the study. This recruitment method could have skewed results, because farms that knowingly have issues with NCD may have neglected to participate due to fear of scrutiny, although the study ensured confidentiality. Likewise, farms experiencing calf-related problems might have wanted to investigate them further at no cost. Selection bias could also have occurred in the fecal samples. We asked veterinarians to randomly collect samples from eligible calves. However, they could have consciously or unconsciously sampled the sickest-looking calves. This could have increased the percentage of samples positive for pathogens that cause more systemic clinical signs (e.g., Salmonella enterica). Linked information regarding management practices at the farms where samples were collected was deliberately not sought. This decision aimed to increase the willingness of farmers to participate in the study. This limited the capacity to investigate which factors were associated with poor colostrum quality, high rates of FTPI, or the prevalence of enteropathogens. However, these factors have been extensively investigated in the literature, and the objective of the study was to provide an estimation of the abovementioned parameters in the Australian dairy system.

\section{CONCLUSIONS}

Collectively, these results indicate that there is still considerable room for improvement of calf management practices in the Australian dairy industry; a great proportion of farms did not meet industry benchmarks. Colostrum management seems to be one of the most important areas to improve, because the prevalence of FTPI, the proportion of colostrum samples not meeting quality standards, and the proportion of farmers not separating calves from dams promptly were considerably high. Strategies to increase awareness of industryrecommended practices for calf management and feeding are needed. Further studies should investigate the drivers of dairy producers to implement these industry standards.

\section{ACKNOWLEDGMENTS}

This study was funded through a New Initiative Grant of the Graham Centre for Agricultural Innovation (Wagga Wagga NSW) and by the Darcy John O'Sullivan Bequest administered by Charles Sturt University. The enteropathogen rapid detection assays were kindly provided by MSD Animal Health Australia. The funders played no role in the design of the study, collection, analysis, or interpretation of data, or the preparation or approval of the manuscript. The authors express their gratitude to all the farmers who completed the survey and to the veterinarians that submitted samples. Similarly, the authors thank Claire Windeyer (University of Calgary, Canada) for assistance with the questionnaire design. The assistance of the Australian Cattle Veterinarians (a special-interest group of the Australian Veterinary Association) and Emily Malone (Graham Centre for Agricultural Innovation) in recruiting veterinarians and farmers, respectively, is also greatly appreciated. Likewise, the authors thank 
Lori Blechynden, Michelle Ayton, and the staff at the Veterinary Diagnostic Laboratory of Charles Sturt University for their help and support. Part of this study was included in the Bachelor of Veterinary Biology/ Bachelor of Veterinary Science (Honours) dissertation of N. Wood. The authors declare no competing interests.

\section{REFERENCES}

Abuelo, A. 2016. Investigation of an outbreak of neonatal calf diarrhoea in a dairy herd. Vet. Rec. Case Rep. 4:e000372. https://doi .org/10.1136/vetreccr-2016-000372.

Abuelo, A., and V. Alves-Nores. 2016. Point-of-care testing in cattle practice: reliability of cow-side diagnostic tests. In Pract. 38:293302. https://doi.org/10.1136/inp.i2704.

APVMA (Australia Pesticides and Veterinary Medicines Authority). 2018. Public Chemical Registration Information System. Accessed Oct. 15, 2018. https://portal.apvma.gov.au/pubcris.

Aust, V., K. Knappstein, H. J. Kunz, H. Kaspar, J. Wallmann, and M. Kaske. 2013. Feeding untreated and pasteurized waste milk and bulk milk to calves: effects on calf performance, health status and antibiotic resistance of faecal bacteria. J. Anim. Physiol. Anim. Nutr. (Berl.) 97:1091-1103. https://doi.org/10.1111/jpn.12019.

Bartier, A. L., M. C. Windeyer, and L. Doepel. 2015. Evaluation of on-farm tools for colostrum quality measurement. J. Dairy Sci. 98:1878-1884. https://doi.org/10.3168/jds.2014-8415.

Besser, T. E., C. C. Gay, and L. Pritchett. 1991. Comparison of three methods of feeding colostrum to dairy calves. J. Am. Vet. Med. Assoc. 198:419-422.

Björkman, C., C. Svensson, B. Christensson, and K. de Verdier. 2003. Cryptosporidium parvum and Giardia intestinalis in calf diarrhoea in Sweden. Acta Vet. Scand. 44:145-152.

Brunton, L. A., D. Duncan, N. G. Coldham, L. C. Snow, and J. R. Jones. 2012. A survey of antimicrobial usage on dairy farms and waste milk feeding practices in England and Wales. Vet. Rec. 171:296. https://doi.org/10.1136/vr.100924.

Cacciò, S. M., and L. Putignani. 2014. Epidemiology of human cryptosporidiosis. Pages 43-79 in Cryptosporidium: Parasite and Disease. M. S. Cacciò and G. Widmer, ed. Springer Vienna, Vienna, Austria.

Catry, B., J. Dewulf, D. Maes, B. Pardon, B. Callens, M. Vanrobaeys, G. Opsomer, A. de Kruif, and F. Haesebrouck. 2016. Effect of antimicrobial consumption and production type on antibacterial resistance in the bovine respiratory and digestive tract. PLoS One 11:e0146488. https://doi.org/10.1371/journal.pone.0146488.

Chuck, G. M., P. D. Mansell, M. A. Stevenson, and M. M. Izzo. 2017. Factors affecting colostrum quality in Australian pasture-based dairy herds. Aust. Vet. J. 95:421-426. https://doi.org/10.1111/ avj.12643.

Constable, P. D. 2004. Antimicrobial use in the treatment of calf diarrhea. J. Vet. Intern. Med. 18:8-17. https://doi.org/10.1892/0891 $-6640(2004) 18<8$ :auitto $>2.0 . c 0 ; 2$.

Constable, P. D., E. Thomas, and B. Boisrame. 2001. Comparison of two oral electrolyte solutions for the treatment of dehydrated calves with experimentally-induced diarrhoea. Vet. J. 162:129-141. https://doi.org/10.1053/tvjl.2000.0553.

Costa, J. H. C., M. A. G. von Keyserlingk, and D. M. Weary. 2016. Invited review: Effects of group housing of dairy calves on behavior, cognition, performance, and health. J. Dairy Sci. 99:2453-2467. https://doi.org/10.3168/jds.2015-10144.

Curtis, G., C. McGregor Argo, D. Jones, and D. Grove-White. 2018. The impact of early life nutrition and housing on growth and reproduction in dairy cattle. PLoS One 13:e0191687. https://doi .org/10.1371/journal.pone.0191687.

Dairy Australia. 2017a. Rearing Healthy Calves. Dairy Australia Limited, Melbourne, Australia. https://www.dairyaustralia.com .au/-/media/dairyaustralia/documents/farm/animal-care/animal -welfare/calf-welfare/rearing-healthy-calves-manual-2nd-ed.ashx.

Dairy Australia. 2017b. Australian Dairy Industry in Focus 2017. Dairy Australia Limited, Melbourne, Australia. https://www .dairyaustralia.com.au/-/media/dairyaustralia/documents/about -dairy-australia/key-publications/in-focus20171117.pdf?la=en\& hash=247A822632F52002BCE966104691BC7D09AC90A4.

de Graaf, D. C., E. Vanopdenbosch, L. M. Ortega-Mora, H. Abbassi, and J. E. Peeters. 1999. A review of the importance of cryptosporidiosis in farm animals. Int. J. Parasitol. 29:1269-1287. https:// doi.org/10.1016/S0020-7519(99)00076-4.

de la Fuente, R., A. García, J. A. Ruiz-Santa-Quiteria, M. Luzón, D. Cid, S. García, J. A. Orden, and M. Gómez-Bautista. 1998. Proportional morbidity rates of enteropathogens among diarrheic dairy calves in central Spain. Prev. Vet. Med. 36:145-152. https:/ /doi.org/10.1016/s0167-5877(98)00077-4.

de la Fuente, R., M. Luzon, J. A. Ruiz-Santa-Quiteria, A. Garcia, D. Cid, J. A. Orden, S. Garcia, R. Sanz, and M. Gomez-Bautista. 1999. Cryptosporidium and concurrent infections with other major enterophatogens in 1 to 30-day-old diarrheic dairy calves in central Spain. Vet. Parasitol. 80:179-185.

Dieguez, F. J., A. M. González, M. Soilán, C. Eiras, M. L. Sanjuán, and E. Yus. 2012. Evaluation of immunochromatographic test strips for rapid diagnosis of neonatal calf diarrhoea. Cattle Pract. $20: 1-4$.

Donovan, G. A., I. R. Dohoo, D. M. Montgomery, and F. L. Bennett. 1998. Calf and disease factors affecting growth in female Holstein calves in Florida, USA. Prev. Vet. Med. 33:1-10.

Drackley, J. K. 2008. Calf nutrition from birth to breeding. Vet. Clin. North Am. Food Anim. Pract. 24:55-86. https://doi.org/10.1016/ j.cvfa.2008.01.001.

Duse, A., K. P. Waller, U. Emanuelson, H. E. Unnerstad, Y. Persson, and B. Bengtsson. 2013. Farming practices in Sweden related to feeding milk and colostrum from cows treated with antimicrobials to dairy calves. Acta Vet. Scand. 55:49. https://doi.org/10.1186/ 1751-0147-55-49.

Duse, A., K. P. Waller, U. Emanuelson, H. E. Unnerstad, Y. Persson, and B. Bengtsson. 2015. Risk factors for antimicrobial resistance in fecal Escherichia coli from preweaned dairy calves. J. Dairy Sci. 98:500-516. https://doi.org/10.3168/jds.2014-8432.

Eckert, E., H. E. Brown, K. E. Leslie, T. J. DeVries, and M. A. Steele. 2015. Weaning age affects growth, feed intake, gastrointestinal development, and behavior in Holstein calves fed an elevated plane of nutrition during the preweaning stage. J. Dairy Sci. 98:6315-6326. https://doi.org/10.3168/jds.2014-9062.

El-Seedy, F. R., A. H. Abed, H. A. Yanni, and S. A. A. Abd El-Rahman. 2016. Prevalence of Salmonella and E. coli in neonatal diarrheic calves. Beni-Seuf Univ. J. Appl. Sci. (Faisalabad) 5:45-51. https://doi.org/10.1016/j.bjbas.2015.11.010.

European Commission. 2014. Commission Regulation (EU) No 1123/2014 of 22 October 2014 amending Directive 2008/38/EC establishing a list of intended uses of animal feedingstuffs for particular nutritional purposes. Official J. Eur. Union 57:81-86.

Fettman, M. J., P. A. Brooks, K. P. Burrows, and R. W. Phillips. 1986. Evaluation of commercial oral replacement formulas in healthy neonatal calves. J. Am. Vet. Med. Assoc. 188:397-401.

Foster, D. M., and G. W. Smith. 2009. Pathophysiology of diarrhea in calves. Vet. Clin. North Am. Food Anim. Pract. 25:13-36.. https:/ /doi.org/10.1016/j.cvfa.2008.10.013.

Garthwaite, B. D., J. K. Drackley, G. C. McCoy, and E. H. Jaster. 1994. Whole milk and oral rehydration solution for calves with diarrhea of spontaneous origin. J. Dairy Sci. 77:835-843.

Gelsinger, S. L., C. M. Jones, and A. J. Heinrichs. 2015. Effect of colostrum heat treatment and bacterial population on immunoglobulin G absorption and health of neonatal calves. J. Dairy Sci. 98:4640-4645. https://doi.org/10.3168/jds.2014-8790.

Geurden, T., D. Berkvens, C. Martens, S. Casaert, J. Vercruysse, and E. Claerebout. 2007. Molecular epidemiology with subtype analysis of Cryptosporidium in calves in Belgium. Parasitology 134:1981-1987. https://doi.org/10.1017/S0031182007003460. 
Godden, S. 2008. Colostrum management for dairy calves. Vet. Clin. North Am. Food Anim. Pract. 24:19-39. https://doi.org/10.1016/ j.cvfa.2007.10.005.

Grimont, P. A. D., and F.-X. Weill. 2007. Antigenic formulae of the Salmonella serovars. 9th ed. WHO Collaborating Centre for Reference and Research on Salmonella, Paris, France.

Gulliksen, S. M., E. Jor, K. I. Lie, I. S. Hamnes, T. Loken, J. Akerstedt, and O. Osteras. 2009. Enteropathogens and risk factors for diarrhea in Norwegian dairy calves. J. Dairy Sci. 92:5057-5066. https://doi.org/10.3168/jds.2009-2080.

Hall, J., and W. Wapenaar. 2012. Opinions and practices of veterinarians and dairy farmers towards herd health management in the UK. Vet. Rec. 170:441. https://doi.org/10.1136/vr.100318.

Heinrichs, A. J. 1993. Raising dairy replacements to meet the needs of the 21st century. J. Dairy Sci. 76:3179-3187. https://doi.org/10 .3168/jds.S0022-0302(93)77656-0.

Ivemeyer, S., M. Walkenhorst, F. Heil, C. Notz, A. Maeschli, G. Butler, and P. Klocke. 2009. Management factors affecting udder health and effects of a one year extension program in organic dairy herds. Animal 3:1596-1604. https://doi.org/10.1017/ S1751731109990498.

Izzo, M., V. Mohler, and J. House. 2011a. Antimicrobial susceptibility of Salmonella isolates recovered from calves with diarrhoea in Australia. Aust. Vet. J. 89:402-408. https://doi.org/10.1111/j .1751-0813.2011.00818.x.

Izzo, M. M., P. D. Kirkland, V. L. Mohler, N. R. Perkins, A. A. Gunn, and J. K. House. 2011b. Prevalence of major enteric pathogens in Australian dairy calves with diarrhoea. Aust. Vet. J. 89:167-173. https://doi.org/10.1111/j.1751-0813.2011.00692.x.

Johnson, J. L., S. M. Godden, T. Molitor, T. Ames, and D. Hagman. 2007. Effects of feeding heat-treated colostrum on passive transfer of immune and nutritional parameters in neonatal dairy calves. J. Dairy Sci. 90:5189-5198. https://doi.org/10.3168/jds.2007-0219.

Kertz, A. F., T. M. Hill, J. D. Quigley 3rd, A. J. Heinrichs, J. G. Linn, and J. K. Drackley. 2017. A 100-year review: Calf nutrition and management. J. Dairy Sci. 100:10151-10172. https://doi.org/10 $.3168 /$ jds.2017-13062.

Kesler, E. M. 1981. Feeding mastitic milk to calves. J. Dairy Sci. 64:719-723. https://doi.org/10.3168/jds.S0022-0302(81)82639-2. (review)

Kohara, J., T. Hirai, K. Mori, H. Ishizaki, and H. Tsunemitsu. 1997. Enhancement of passive immunity with maternal vaccine against newborn calf diarrhea. J. Vet. Med. Sci. 59:1023-1025.

Lago, A., S. M. McGuirk, T. B. Bennett, N. B. Cook, and K. V. Nordlund. 2006. Calf respiratory disease and pen microenvironments in naturally ventilated calf barns in winter. J. Dairy Sci. 89:40144025. https://doi.org/10.3168/jds.S0022-0302(06)72445-6.

Langkjaer, R. B., H. Vigre, H. L. Enemark, and C. Maddox-Hyttel. 2007. Molecular and phylogenetic characterization of Cryptosporidium and Giardia from pigs and cattle in Denmark. Parasitology 134:339-350. https://doi.org/10.1017/S0031182006001533.

Uhde, F. L., T. Kaufmann, H. Sager, S. Albini, R. Zanoni, E. Schelling, and M. Meylan. 2008. Prevalence of four enteropathogens in the faeces of young diarrhoeic dairy calves in Switzerland. Vet. Rec. 163:362-366. https://doi.org/10.1136/vr.163.12.362.

Lorenz, I., J. Fagan, and S. J. More. 2011. Calf health from birth to weaning. II. Management of diarrhoea in pre-weaned calves. Ir. Vet. J. 64:9. https://doi.org/10.1186/2046-0481-64-9.

Lundborg, G. K., E. C. Svensson, and P. A. Oltenacu. 2005. Herd-level risk factors for infectious diseases in Swedish dairy calves aged 0-90 days. Prev. Vet. Med. 68:123-143. https://doi.org/10.1016/j .prevetmed.2004.11.014.

Mainar-Jaime, R. C., S. Andres, J. P. Vico, B. San Roman, V. Garrido, and M. J. Grillo. 2013. Sensitivity of the ISO 6579:2002/ Amd 1:2007 standard method for detection of Salmonella spp. on mesenteric lymph nodes from slaughter pigs. J. Clin. Microbiol. 51:89-94. https://doi.org/10.1128/JCM.02099-12.

Malorny, B., J. Hoorfar, C. Bunge, and R. Helmuth. 2003. Multicenter validation of the analytical accuracy of Salmonella PCR: towards an international standard. Appl. Environ. Microbiol. 69:290-296. https://doi.org/10.1128/aem.69.1.290-296.2003.
McAloon, C. G., M. L. Doherty, J. Donlon, I. Lorenz, J. Meade, L. O'Grady, and P. Whyte. 2016. Microbiological contamination of colostrum on Irish dairy farms. Vet. Rec. 178:474. https://doi.org/ $10.1136 / v r .103641$.

McGuirk, S. M. 2011. Management of dairy calves from birth to weaning. Pages $175-193$ in Dairy Production Medicine. C. A. Risco and P. Melendez-Retamal, ed. Blackwell Publishing Ltd., West Sussex, UK.

Mee, J. F. 2013. Why do so many calves die on modern dairy farms and what can we do about calf welfare in the future? Animals (Basel) 3:1036-1057. https://doi.org/10.3390/ani3041036.

Morrill, K. M., E. Conrad, A. Lago, J. Campbell, J. Quigley, and H. Tyler. 2012. Nationwide evaluation of quality and composition of colostrum on dairy farms in the United States. J. Dairy Sci. 95:3997-4005. https://doi.org/10.3168/jds.2011-5174.

Murray, C. F., L. J. Fick, E. A. Pajor, H. W. Barkema, M. D. Jelinski, and M. C. Windeyer. 2016. Calf management practices and associations with herd-level morbidity and mortality on beef cowcalf operations. Animal 10:468-477. https://doi.org/10.1017/ S1751731115002062.

NAHMS (National Animal Health Monitoring Service). 2014. Dairy 2014. Part 1: Reference of Dairy Health and Management in the United States. USDA, APHIS Veterinary Services, Ft. Collins, CO.

Nielsen, L. R., Y. H. Schukken, Y. T. Grohn, and A. K. Ersboll. 2004 Salmonella Dublin infection in dairy cattle: Risk factors for becoming a carrier. Prev. Vet. Med. 65:47-62. https://doi.org/10.1016/j .prevetmed.2004.06.010.

O'Handley, R. M., C. Cockwill, T. A. McAllister, M. Jelinski, D. W. Morck, and M. E. Olson. 1999. Duration of naturally acquired giardiosis and cryptosporidiosis in dairy calves and their association with diarrhea. J. Am. Vet. Med. Assoc. 214:391-396.

Oliveira, C., L. Oliveira, S. Carvalho, and P. Naves. 2005. Detection of Salmonella enterica in porcine faecal samples by different isolating and enrichment broth cultivation-PCR methods. Rev. Port. Ciênc. Vet. 100:193-198.

Olson, M. E., R. M. O'Handley, B. J. Ralston, T. A. McAllister, and R. C. Thompson. 2004. Update on Cryptosporidium and Giardia infections in cattle. Trends Parasitol. 20:185-191. https://doi.org/ 10.1016/j.pt.2004.01.015.

Parker, K. I., C. W. Compton, F. M. Anniss, A. M. Weir, and S. McDougal. 2007. Management of dairy heifers and its relationships with the incidence of clinical mastitis. N. Z. Vet. J. 55:208-216. https://doi.org/10.1080/00480169.2007.36770.

Phipps, A. J., D. S. Beggs, A. J. Murray, P. D. Mansell, and M. F. Pyman. 2018. A survey of northern Victorian dairy farmers to investigate dairy calf management: Calf-rearing practices. Aust. Vet. J. 96:107-110. https://doi.org/10.1111/avj.12686.

Phipps, A. J., D. S. Beggs, A. J. Murray, P. D. Mansell, M. A. Stevenson, and M. F. Pyman. 2016. Survey of bovine colostrum quality and hygiene on northern Victorian dairy farms. J. Dairy Sci. 99:8981-8990. https://doi.org/10.3168/jds.2016-11200.

Raboisson, D., P. Trillat, and C. Cahuzac. 2016. Failure of passive immune transfer in calves: A meta-analysis on the consequences and assessment of the economic impact. PLoS One 11:e0150452. https: //doi.org/10.1371/journal.pone.0150452.

Reif, J. S., L. Wimmer, J. A. Smith, D. A. Dargatz, and J. M. Cheney. 1989. Human cryptosporidiosis associated with an epizootic in calves. Am. J. Public Health 79:1528-1530.

Reynolds, D. J., J. H. Morgan, N. Chanter, P. W. Jones, J. C. Bridger, T. G. Debney, and K. J. Bunch. 1986. Microbiology of calf diarrhoea in southern Britain. Vet. Rec. 119:34-39.

Rogan, W. J., and B. Gladen. 1978. Estimating prevalence from the results of a screening test. Am. J. Epidemiol. 107:71-76.

Silverlås, C., C. Bjorkman, and A. Egenvall. 2009. Systematic review and meta-analyses of the effects of halofuginone against calf cryptosporidiosis. Prev. Vet. Med. 91:73-84. https://doi.org/10.1016/j .prevetmed.2009.05.003.

Smith, D. R. 2012. Field disease diagnostic investigation of neonatal calf diarrhea. Vet. Clin. North Am. Food Anim. Pract. 28:465-481. https://doi.org/10.1016/j.cvfa.2012.07.010. 
Smith, G. W. 2009. Treatment of calf diarrhea: Oral fluid therapy. Vet. Clin. North Am. Food Anim. Pract. 25:55-72. https://doi.org/10 .1016/j.cvfa.2008.10.006.

Smith, G. W., and J. Berchtold. 2014. Fluid therapy in calves. Vet Clin. North Am. Food Anim. Pract. 30:409-427. /https://doi.org/ 10.1016/j.cvfa.2014.04.002.

Stewart, S., S. Godden, R. Bey, P. Rapnicki, J. Fetrow, R. Farnsworth, M. Scanlon, Y. Arnold, L. Clow, K. Mueller, and C. Ferrouillet. 2005. Preventing bacterial contamination and proliferation during the harvest, storage, and feeding of fresh bovine colostrum. J. Dairy Sci. 88:2571-2578. https://doi.org/10.3168/jds.S0022 -0302(05)72933-7.

Svensson, C., K. Lundborg, U. Emanuelson, and S. O. Olsson. 2003 Morbidity in Swedish dairy calves from birth to 90 days of age and individual calf-level risk factors for infectious diseases. Prev. Vet. Med. 58:179-197. https://doi.org/10.1016/S0167-5877(03)00046 -1 .

Trotz-Williams, L. A., B. D. Jarvie, A. S. Peregrine, T. F. Duffield, and K. E. Leslie. 2011. Efficacy of halofuginone lactate in the prevention of cryptosporidiosis in dairy calves. Vet. Rec. 168:509. https://doi.org/10.1136/vr.d1492.
Uhde, F. L., T. Kaufmann, H. Sager, S. Albini, R. Zanoni, E. Schelling, and M. Meylan. 2008. Prevalence of four enteropathogens in the faeces of young diarrhoeic dairy calves in Switzerland. Vet. Rec. 163:362-366.

Vogels, Z. 2010. Calf fluid therapy made simple. Pages 1-8 in Proc. Australian Cattle Veterinarians Annual Conference. Australian Cattle Veterinarians, Alice Springs, NT, Australia.

Vogels, Z., G. M. Chuck, and J. M. Morton. 2013. Failure of transfer of passive immunity and agammaglobulinaemia in calves in southwest Victorian dairy herds: Prevalence and risk factors. Aust. Vet. J. 91:150-158. https://doi.org/10.1111/avj.12025.

Windeyer, M. C., K. E. Leslie, S. M. Godden, D. C. Hodgins, K. D. Lissemore, and S. J. LeBlanc. 2014. Factors associated with morbidity, mortality, and growth of dairy heifer calves up to 3 month of age. Prev. Vet. Med. 113:231-240. https://doi.org/10.1016/j .prevetmed.2013.10.019.

Xiao, L., L. Zhou, M. Santin, W. Yang, and R. Fayer. 2007. Distribution of Cryptosporidium parvum subtypes in calves in eastern United States. Parasitol. Res. 100:701-706. https://doi.org/10 .1007/s00436-006-0337-2. 